\title{
OPPA Regimen
}

National Cancer Institute

\section{Source}

National Cancer Institute. OPPA Regimen. NCI Thesaurus. Code C67163.

A reg imen consisting of vincristine, prednisone, procarbazine and doxorubicin (OPPA) used in combination with radiation therapy for the treatment of female patients with childhood Hodgkin lymphoma with low-risk features. 